\title{
The Simplest Way to Iodine-Doped Anatase for Photocatalysts Activated by Visible Light
}

\author{
Václav Štengl and Tomáš Matys Grygar \\ Department of Solid State Chemistry, Institute of Inorganic Chemistry AS CR v.v.i., 25068 Řez, Czech Republic \\ Correspondence should be addressed to Václav Štengl, stengl@iic.cas.cz
}

Received 12 July 2011; Revised 28 August 2011; Accepted 29 August 2011

Academic Editor: Jimmy Yu

Copyright ( 2011 V. Štengl and T. M. Grygar. This is an open access article distributed under the Creative Commons Attribution License, which permits unrestricted use, distribution, and reproduction in any medium, provided the original work is properly cited.

\begin{abstract}
Iodine-doped $\mathrm{TiO}_{2}$ was prepared by thermal hydrolysis of aqueous solutions of the titanium peroxo-complex, which includes no organic solvents or organometallic compounds. The synthesized samples were characterized by X-ray diffraction (XRD), Raman spectroscopy (RS), infrared spectroscopy (IR), specific surface area (BET), and porosity determination (BJH). The morphology and particle size was determined by high-resolution transmission electron microscopy (HRTEM) and selected area electron diffraction (SAED). All prepared samples have a red-shifted band-gap transition, well crystalline anatase structure, and porous particles with a $100-200 \mathrm{~m}^{2} \mathrm{~g}^{-1}$ specific surface area. The photocatalytic activity of iodine-doped titania samples was determined by decomposition of Orange II dye during irradiation at $365 \mathrm{~nm}$ and $400 \mathrm{~nm}$. Iodine doping promotes the titania photocatalytic activity very efficiently under visible light irradiation. The titania sample with $0.32 \mathrm{wt} . \%$ I has the highest catalytic activity during the photocatalyzed degradation of Orange II dye in an aqueous suspension in the UV and visible regions.
\end{abstract}

\section{Introduction}

The improvement of the photocatalytic activity of $\mathrm{TiO}_{2}$ by shifting its activating irradiation to the visible region is the primary focus of recent $\mathrm{TiO}_{2}$ research. An intensive effort has been devoted to achieve the utilization of visible light via nonmetal or transitional metal ion doping of $\mathrm{TiO}_{2}$. Nonmetal doping opens up a new possibility for the development of solar or day light-induced photocatalytic materials. The doping $\mathrm{TiO}_{2}$ with nonmetals such as $\mathrm{B}[1], \mathrm{C}$ [2], N [3], S [4, 5], or Se [6] and Te [7] extends the absorption wavelengths from UV to visible region to enhance photocatalytic activity. Very recently, researchers have reported several halogen dopants such as $\mathrm{F}[8,9], \mathrm{Cl}[10,11]$, and $\mathrm{Br}[12,13]$ and demonstrated their higher photocatalytic activity under $\mathrm{UV}$ as well as visible light irradiation.

Iodine-doped $\mathrm{TiO}_{2}$ powders prepared via hydrothermal treatment of a sol-gel prepared precursor from isopropyl titanate, $\mathrm{Ti}\left[\mathrm{OCH}\left(\mathrm{CH}_{3}\right)_{2}\right]_{4}$ and iodic acid $\mathrm{HIO}_{3}$ have had absorption in the region of ultraviolet and visible light and were used as a photocatalyst with the irradiation of
UV or visible light [14]. A visible light-activated photocatalyst of iodine-doped $\mathrm{TiO}_{2}$ was synthesized by direct hydrolysis of the tetrabutyl titanate $\mathrm{Ti}\left[\mathrm{OC}_{4} \mathrm{H}_{9}\right]_{4}$. Iodinedoped $\mathrm{TiO}_{2}$ exhibited stronger absorption in the visible light range with a red shift in the band gap transition [15]. Multivalence iodine- $\left(\mathrm{I}^{7+} / \mathrm{I}^{-}\right)$doped $\mathrm{TiO}_{2}$ was prepared by combining the of deposition-precipitation process and hydrothermal treatment of $\mathrm{Ti}\left(\mathrm{SO}_{4}\right)_{2}$ and $\mathrm{KIO}_{3}$. Electronic structure calculations on the basis of the density functional theory revealed that upon doping, new states that originated from the $\mathrm{I}$ atom of the $\mathrm{IO}_{4}$ group are observed near the lower conduction-band region of $\mathrm{TiO}_{2}$, and excitation from the valence band of $\mathrm{TiO}_{2}$ to the surface $\mathrm{IO}^{4-}$ are responsible for the visible-light response of the I-doped $\mathrm{TiO}_{2}$ [16]. Iodine-doped titanium oxide nanoparticles that are photocatalytically responsive to visible light illumination have been synthesized by the hydrothermal method. The photocatalytic activities of the $\mathrm{I}-\mathrm{TiO}_{2}$ powders were investigated by photocatalytic reduction of $\mathrm{CO}_{2}$ with $\mathrm{H}_{2} \mathrm{O}$ under visible light and also under UV-vis illumination. Carbon monoxide was found to be the major photoreduction 
TABLE 1: Experimental conditions, EDX analysis, surface area, porosity, and particle size.

\begin{tabular}{|c|c|c|c|c|c|c|c|}
\hline Sample & $\mathrm{KI}[\mathrm{g}]$ & EDX I [wt.\%] & $\begin{array}{c}\text { Specific surface } \\
\text { Area }\left[\mathrm{m}^{2} \mathrm{~g}^{-1}\right]\end{array}$ & $\begin{array}{l}\text { Pore volume } \\
{\left[\mathrm{cm}^{3} \mathrm{~g}^{-1}\right]}\end{array}$ & $\begin{array}{c}\text { Micropore } \\
\text { surface area } \\
{\left[\mathrm{m}^{2} \mathrm{~g}^{-1}\right]}\end{array}$ & $\begin{array}{l}\text { Micropore volume } \\
\qquad\left[\mathrm{cm}^{3} \mathrm{~g}^{-1}\right]\end{array}$ & $\begin{array}{l}\text { Crystallite } \\
\text { size }[\mathrm{nm}]\end{array}$ \\
\hline TiP_I01 & 0.1 & 0.10 & 172.3 & 0.6144 & 8.32 & 0.00292 & 32.2 \\
\hline TiP_I03 & 0.3 & 0.05 & 184.1 & 0.6300 & 2.13 & 0.00010 & 30.8 \\
\hline TiP_I05 & 0.5 & 0.10 & 209.9 & 0.6486 & 0.58 & 0.00002 & 30.5 \\
\hline TiP_I07 & 0.7 & 0.32 & 199.9 & 0.5655 & 3.76 & 0.00072 & 30.5 \\
\hline TiP_I10 & 1.0 & 0.30 & 177.4 & 0.8134 & - & - & 33.4 \\
\hline TiP_I30 & 3.0 & 0.20 & 149.8 & 0.6340 & - & - & 33.5 \\
\hline TiP_I50 & 5.0 & 0.61 & 143.2 & 0.6247 & - & - & 31.6 \\
\hline TiP_I70 & 7.0 & 0.72 & 180.7 & 0.6459 & 11.53 & 0.00448 & 31.3 \\
\hline
\end{tabular}

product using both doped and undoped $\mathrm{TiO}_{2}$ [17]. Titanium tetrafluoride $\mathrm{TiF}_{4}$ and $\mathrm{HIO}_{4}$ acid were used as antecedents for the $\mathrm{TiO}_{2}$ precursor and iodine dopant to synthesize $\mathrm{Ti}_{\mathrm{a}}\left(\mathrm{IO}_{4}\right)_{\mathrm{b}} \mathrm{F}_{\mathrm{c}}$ intermediate compounds. In a typical synthesis procedure, $\mathrm{TiF}_{4}$ powder precursor was dissolved into an aqueous solution of $1 \mathrm{M} \mathrm{HIO}_{4}$, followed by hydrothermal treatment in a Teflon-lined autoclave at $180^{\circ} \mathrm{C}$ for $12 \mathrm{~h}$ [18]. Iodine-doped mesoporous titania with a bicrystalline (anatase and rutile) framework was synthesized by a twostep hydrothermal synthesis process using a block copolymer as a template from $\operatorname{Ti}\left[\mathrm{OCH}\left(\mathrm{CH}_{3}\right)_{2}\right]_{4}$ and iodic acid [19]; the anatase crystalline phase and mesoporous structure were synthesized by means of a simple triblock copolymer-mediated sol-gel method at the low temperature of $120^{\circ} \mathrm{C}$ [20]. Nanocrystalline I-F-codoped $\mathrm{TiO}_{2}$ was prepared by a sol-gel-impregnation method, using tetrabutylorthotitanate in a mixed $\mathrm{NH}_{4} \mathrm{I}-\mathrm{NH}_{4} \mathrm{~F}$ aqueous solution. The photocatalytic activity of as-prepared I-F-codoped $\mathrm{TiO}_{2}$ was remarkably higher than that of pure, I-doped, and F-doped $\mathrm{TiO}_{2}[21]$.

Other works have reported on $\mathrm{TiO}_{2}$ codoped with cerium and iodine [22], gallium and iodine [23], and neodymium and iodine [24]. This work focuses on the structure, morphology, and photocatalytic performance of pure $\mathrm{TiO}_{2}$ and $\mathrm{IO}_{3}{ }^{-}$-doped $\mathrm{TiO}_{2}$ nanoparticles. The high activity of $\mathrm{IO}_{3}{ }^{-}$doped $\mathrm{TiO}_{2}$ is strongly dependent on the size, shape, surface area, formation mixed phases, and distribution of iodine nanoparticles on titanium surfaces [25].

The objective of this paper is to report on the influence of the incorporation of iodine into monodispersed spindle-like anatase particles. Eight samples labeled as TiP_I01-TiP_I70 were prepared using a very simple thermal hydrolysis of aqueous solution of $\mathrm{KI}$ and a titanium peroxo-complex. The procedure avoids using expensive and unstable Ti raw materials. All yet reported I-doped titania specimens have been prepared from Ti-alkoxides, $[5,14,15,19,20]$ or $\mathrm{TiF}_{4}$, or they have employed hydrothermal reaction [26]. These studies introduced and described that catalyst. The novelty of our work is actually a synthesis method avoiding the alkoxides in aim to meet economical and ecological requirements for possible wide-scale production. The photocatalytic activity of the as-prepared doped titania was assessed by the photocatalytic decomposition of Orange II dye in an aqueous slurry under irradiation at wavelengths of 365 and $400 \mathrm{~nm}$.

\section{Synthesis of I-Doped Titania}

All chemicals used titanium oxo-sulphate $\left(\mathrm{TiOSO}_{4}\right)$, potassium iodide (KI), ammonium hydroxide $\left(\mathrm{NH}_{4} \mathrm{OH}\right)$, and hydrogen peroxide $\left(\mathrm{H}_{2} \mathrm{O}_{2}\right)$ were of analytical grade and were supplied by a Sigma-Aldrich Ltd (Czech republic).

In a typical experiment, $100 \mathrm{~mL} 1.6 \mathrm{M}$ solution of titanium oxo-sulphate was diluted with distilled water to volume $2 \mathrm{~L}$ and hydrolyzed by the slow addition of ammonium hydroxide solution (10\%) under constant stirring at a temperature of $0^{\circ} \mathrm{C}$ an ice bath, until the reaction mixture reached $\mathrm{pH}$ 8.0. The obtained white precipitate was separated by filtration and washed with distilled water until it was free of sulphate ions (confirmed by the $\mathrm{BaCl}_{2}$ test). The obtained wet precipitate was mixed with $100 \mathrm{~mL}$ of a $30 \%$ hydrogen peroxide solution that produced a homogeneous yellow gelatinous mass. That mass was subsequently mixed with defined amount of potassium iodide KI which was added. (see Table 1 for the stoichiometry). The yellow gelatinous mass changed color to dark orange. The reaction mixture was refluxed in a round-bottom flask on a heating mantle. During the heating, a yellowish white precipitate was formed. Refluxing continued till the color of the precipitate changed to white, that is, for 36 hours. The obtained doped titania was air-dried at $105^{\circ} \mathrm{C}$.

\section{Characterization Methods}

Diffraction patterns were collected with diffractometer PANalytical X'Pert PRO equipped with a conventional Xray tube $(\mathrm{Cu} \mathrm{K} \alpha$ radiation, $40 \mathrm{kV}, 30 \mathrm{~mA})$ and a linear position sensitive detector PIXcel with an antiscatter shield. A programmable divergence slit set to a fixed value of 0.5 degrees, Soller slits of $0.02 \mathrm{rad}$, and a mask of $15 \mathrm{~mm}$ were used in the primary beam. A programmable antiscatter slit set to a fixed value of 0.5 degrees, Soller slit of $0.02 \mathrm{rad}$, and a $\mathrm{Ni}$ beta-filter were used in the diffracted beam. A qualitative analysis was performed with the DiffracPlus Eva software 
package (Bruker AXS, Germany) using the JCPDS PDF-2 database [27]. For a quantitative analysis of XRD patterns, we used Diffrac-Plus Topas (Bruker AXS, Germany, version 4.1) with structural models based on an ICSD database [28]. This program makes it possible to estimate the weight fractions of crystalline phases and mean coherence length by following of Rietveld refinement procedure.

The specific surface areas of samples were determined from nitrogen adsorption-desorption isotherms at a liquid nitrogen temperature using a Coulter SA3100 instrument with outgas $15 \mathrm{~min}$ at $150^{\circ} \mathrm{C}$. The Brunauer-Emmett-Teller (BET) method was used for the surface area calculation [29] and the pore size distribution (pore diameter, pore volume, and micropore surface area of the samples) was determined by the Barrett-Joyner-Halenda (BJH) method [30].

The morphology of sample powders was inspected by transmission electron microscopy (TEM), and the crystal structure was analyzed by electron diffraction (ED) using a $200 \mathrm{kV}$ TEM microscope JEOL 2010F and 300 kV JEOL 3010. As specimen support for TEM investigations, a microscopic copper grid covered by a thin transparent carbon film was used. Both samples were studied in a bright field and by electron diffraction with a selecting aperture (SAED) mode at an acceleration voltage of $200 \mathrm{kV}$.

Diffuse reflectance UV/VIS spectra for the evaluation of photophysical properties were recorded in the diffuse reflectance mode $(\mathrm{R})$ and transformed to absorption spectra through the Kubelka-Munk function [31]. A Perkin Elmer Lambda 35 spectrometer equipped with a Labsphere RSAPE20 integration sphere with $\mathrm{BaSO}_{4}$ as a standard was used.

Raman spectra were obtained with a DXR Raman Microscope (Thermo Scientific, USA). A $532 \mathrm{~nm}$ laser was used at a power of $3 \mathrm{~mW}$. Powdered samples were scanned at a 15-point mapping mode under a $10 \mathrm{x}$ objective in an automated autofocus mode.

Infrared spectra were recorded using a Thermo-Nicolet Nexus 670 FT-IR spectrometer approximately in the region $4000-500$ and $500-50 \mathrm{~cm}^{-1}$, respectively, with a single-reflection horizontal accessory on a Si crystal. The samples were pressed into $\mathrm{KBr}$ pellets at ambient conditions and measured in the transmission mode.

XPS high vacuum chamber was equipped with SPECS X-Ray XR50 (Al cathode $1486.6 \mathrm{eV}$ ) and SPECS PHOIBOS 100 Hemispheric Analyzer with 5-channels detector. The XPS spectra were taken in position perpendicular to sample surface. The XPS chamber was connected to process chamber for ion etching and surface modifications. Background pressure in XPS was under $4.0 \mathrm{E}^{-9}$ mbar. XPS survey-scan spectra were made at pass energy of $40 \mathrm{eV}$; the energy resolution was set to $0.5 \mathrm{eV}$. The atomic concentration of compounds was calculated with RSF defined in standard table of CasaXPS.

XPS apparatus was equipped with SPECS X-Ray XR50 (Al cathode $1486.6 \mathrm{eV}$ ) and SPECS PHOIBOS $100 \mathrm{Hemi-}$ spheric Analyzer with 5-channels detector. A background pressure in XPS during the measurements was under 2 $\times 10^{-8}$ mbar. XPS survey-scan spectra were made at pass energy of $40 \mathrm{eV}$; the energy resolution was set to $0.5 \mathrm{eV}$, while individual high-resolution spectra were taken at pass energy

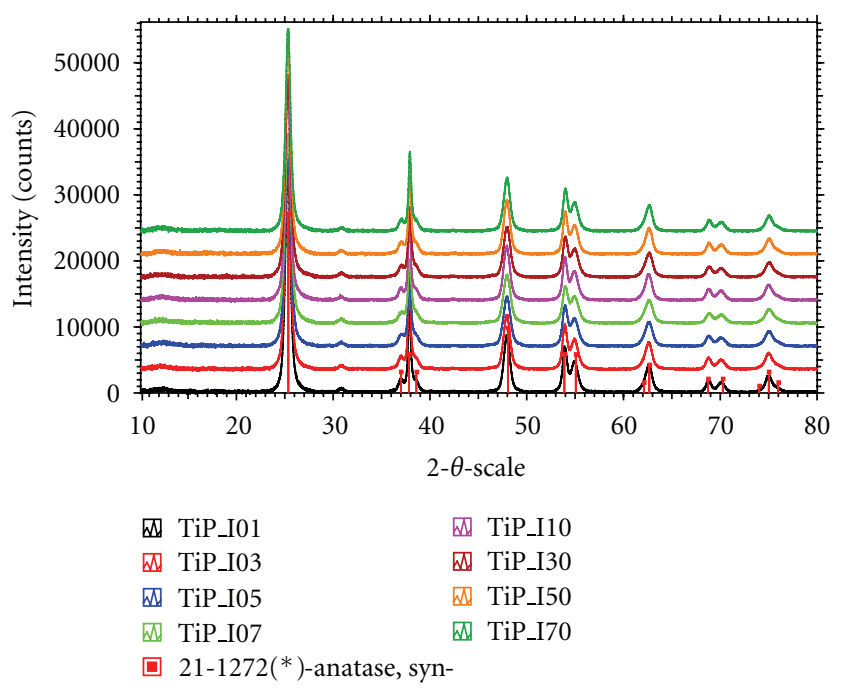

FIgURE 1: XRD patterns of iodine-doped $\mathrm{TiO}_{2}$.

of $10 \mathrm{eV}$ with $0.05 \mathrm{eV}$ energy steps. A software tool CasaXPS was used to fit high-resolution multicomponents peaks. The proper surface charge compensation was done by fitting $\mathrm{C}-\mathrm{C}, \mathrm{C}-\mathrm{H}$ component of $\mathrm{C}$ 1s peak to reference-binding energy $284.5 \mathrm{eV}$. The atomic concentration of compounds was evaluated with relative sensitivity factors (RSF) defined in standard table of CasaXPS software.

Photocatalytic activity of samples was assessed from the kinetics of the photocatalytic degradation of $0.02 \mathrm{M}$ Orange II dye (sodium salt 4-[(2-hydroxy-1-naphtenyl)azo]benzene- sulfonic acid) in aqueous slurries. The azo-dyes (Orange II, Methyl Red, Congo Red, etc.) are not absorbed on titania surfaces in contrast to methylene blue. For azodye degradation, the complete mass balance in nitrogen indicated that the central $-\mathrm{N}=\mathrm{N}-$ azo-group was converted in gaseous dinitrogen, which is ideal for the elimination of nitrogen-containing pollutants, not only for environmental photocatalysis but also for any physicochemical method [32]. Direct photolysis employing artificial UV light or a solar energy source cannot mineralize Orange II [33]. Kinetics of the photocatalytic degradation of aqueous Orange II dye solution was measured by using a self-constructed photoreactor [34] which consists of a stainless steel cover and quartz tube with fluorescent lamp Narva with $13 \mathrm{~W}$ power and light intensity of $\sim 3.5 \mathrm{mWcm}^{-2}$. Black light ( $365 \mathrm{~nm}$ ) for UV and warm white (above $400 \mathrm{~nm}$ ) for visible light irradiation were used. An Orange II dye solution was circulated by means of a membrane pump through a flow cuvette. The concentration of Orange II dye was determined by measuring absorbance at the $480 \mathrm{~nm}$ with VIS spectrophotometer ColorQuestXE. A $0.5 \mathrm{~g}$ sample of titania was sonicated for 10 min with an ultrasonic bath $(300 \mathrm{~W}, 35 \mathrm{kHz})$ before the kinetic experiments. The $\mathrm{pH}$ of the resulting suspension was taken as the initial value for neutral conditions and under the experiment was kept at the value 7.0. 


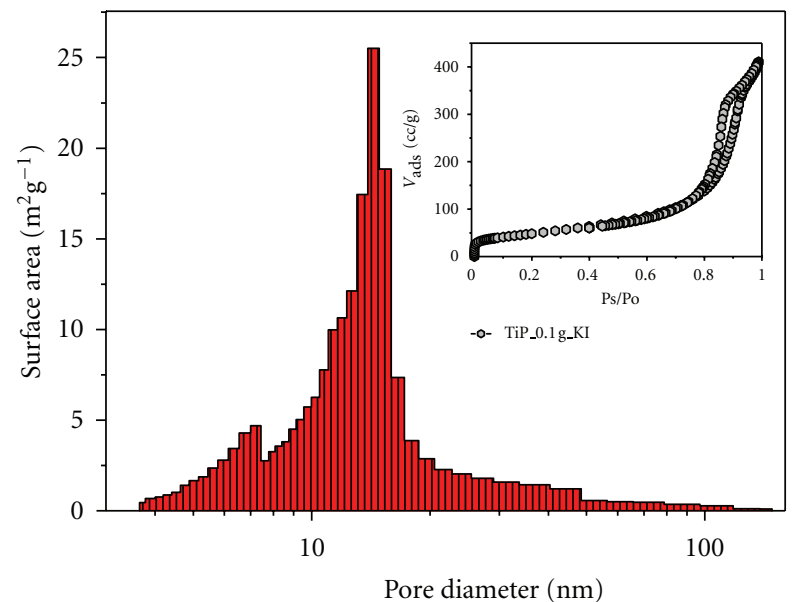

— TiP_I01

(a)

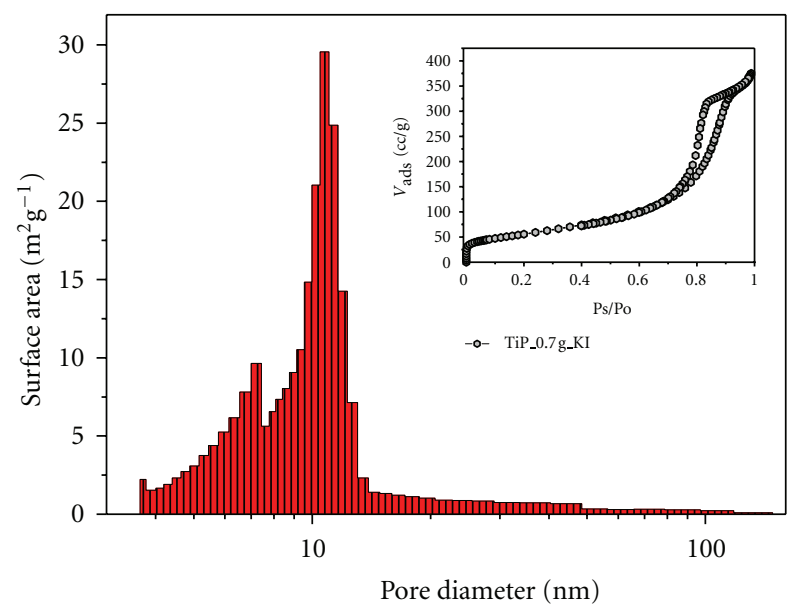

— TiP_I07

(c)



— TiP_I50



- TiP_I05

(b)



- TiP_I10

(d)

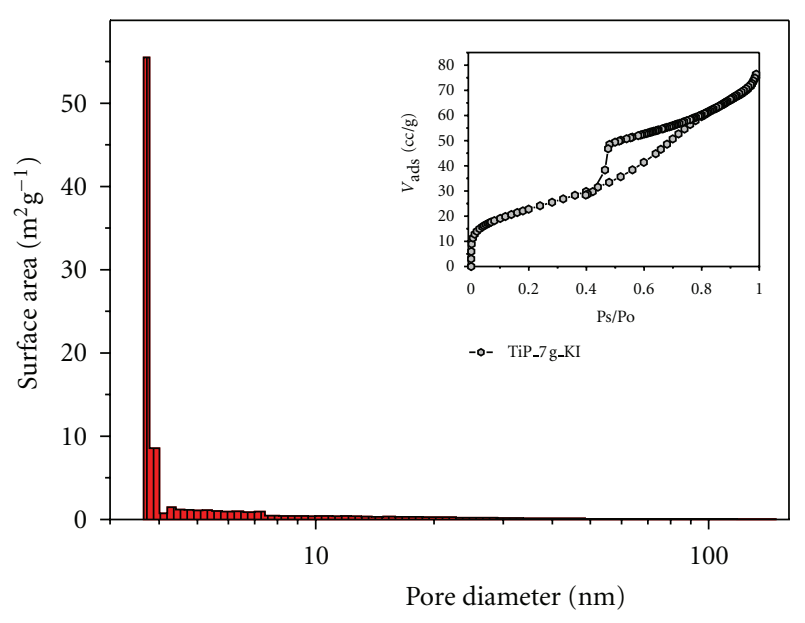

- TiP_I70

(e)

(f)

FIGURE 2: BJH pore size distribution plots of desorption pore area versus pore radius, (a) TiP_I01, (b) TiP_I05, (c) TiP_I07, (d) TiP_I10, (e) TiP_I50, and (f) TiP_I70. Inset is the hysteresis loop. 




Figure 3: Raman spectra of iodine-doped $\mathrm{TiO}_{2}$ and reference sample P25.



FIgURE 4: Infrared spectra of iodine-doped $\mathrm{TiO}_{2}$.

\section{Results and Discussions}

The XRD patterns of the $\mathrm{Ge}^{4+}$-doped titania samples are shown in Figure 1. Only the diffraction lines of anatase (ICDD PDF 21-1272) can be seen. The substitution of $\mathrm{I}^{5+}$ for $\mathrm{Ti}^{4+}$ is possible, because they have respective ionic radii of 0.0620 [35] and 0.0605 [36] $\mathrm{nm}$ for $\mathrm{I}^{5+}$ and $\mathrm{Ti}^{4+}$. The crystallite size calculated by Rietveld refinement is presented in Table 1.

The specific surface area of the as-prepared samples, calculated according to the multipoint Brunauer-Emmett-Teller (BET) method, total pore volume, micropore surface area, and micropore volume is listed in Table 1. The BarrettJoyner-Halenda (BJH) pore-size distribution plot and nitrogen adsorption/desorption isotherms of as-prepared samples are shown in Figure 2 (inset). According to the IUPAC notation [37], microporous materials have pore diameters of less than $2 \mathrm{~nm}$, and macroporous materials have pore diameters of greater than $50 \mathrm{~nm}$; the mesoporous category thus lies in the middle. The mean pore size of all samples, except the sample denoted $\mathrm{Ti} \_\mathrm{I}$, is around $\sim 15-20 \mathrm{~nm}$, the pore size distribution being relatively narrow. The sample Ti_I7 have porosity on the edge of mesoporous and microporous textures or about $\sim 3 \mathrm{~nm}$. The all samples have a type IV isotherm, since it is characteristic of mesoporous material with type a $\mathrm{H} 2$ hysteresis, since it is a characteristic of large-pore mesoporous materials and can be ascribed to capillary condensation in mesopores. The high steepness of the hysteresis indicates the high order of mesoporosity. All samples are characteristic of the Type A hysteresis loop according to Bore's characterization [38]. This hysteresis type is connected with pores in the form of capillary tubes (open at both ends), wide ink-bootle like pores and wedge-shaped capillaries. In addition, the sample containing Ti_I01, Ti_I03, Ti_I05, Ti_I07, and Ti_I70 also has a microporous texture and have micropore surface area between $\sim 2-12 \mathrm{~m}^{2} \mathrm{~g}^{-1}$.

The Raman spectra of series samples Ti_I and P25 selected as a reference, is presented in Figure 3. The specific vibration modes are located at $143 \mathrm{~cm}^{-1}(\mathrm{Eg}), 399 \mathrm{~cm}^{-1}$ (B1g), $515 \mathrm{~cm}^{-1}(\mathrm{~B} 1 \mathrm{~g}+\mathrm{A} 1 \mathrm{~g})$, and $638 \mathrm{~cm}^{-1}(\mathrm{Eg})$, indicating the presence of the anatase phase in all of these samples. It has been shown that the Raman-active mode change is quite sensitive to the configurations of dopant, in which I$\mathrm{O}-\mathrm{I}$ bonds incorporated in a Ti-O-Ti network can cause a shift of Eg modes only at 143 and $640 \mathrm{~cm}^{-1}$ towards higher wavenumbers [19], while I-O-Ti bonds can generate two new active modes in anatase $\mathrm{TiO}_{2}$ at 182 and $192 \mathrm{~cm}^{-1}$ [18].

Compared to P25, there is not a notable shift to higher wavenumbers for the two mentioned Raman peaks of TiP_I of Eg modes at 144 and $640 \mathrm{~cm}^{-1}$, but the Raman peaks are much broader for I-doped nanocrystal titania samples. Two factors, including size effect and doping and the shift and broadening of Raman peaks, should be considered. As expected from the confinement theory, all peaks get narrower as the crystallite size increases [39], and the Raman band shift and broadening are attributed to the effects of decreasing particle size [40]. The effect of broadening compared to the particle size of P25 [41] in the spectra of I-doped titania nanoparticles has been observed, and it was suggested that broadening the Raman spectra of titania could be not caused by the effect of particle size on the force constants and vibrational amplitudes. For this reason, the Raman peaks are probably broadened for the iodine-doped $\mathrm{TiO}_{2}$ with respect to the compared sample P25. The sample denoted Ti_I70 with the content of $0.72 \mathrm{wt} . \%$ of iodine has a small peak at $106 \mathrm{~cm}^{-1}$, which can be assigned to vibration mode of iodine $\mathrm{A}_{1 \mathrm{~g}}[35]$ in interstitial sites or surface of titania.

Figure 4 show the IR spectrum of the iodine-doped titania prepared by thermal hydrolysis of titania peroxocomplexes. The broad absorption peaks about $3400 \mathrm{~cm}^{-1}$ 


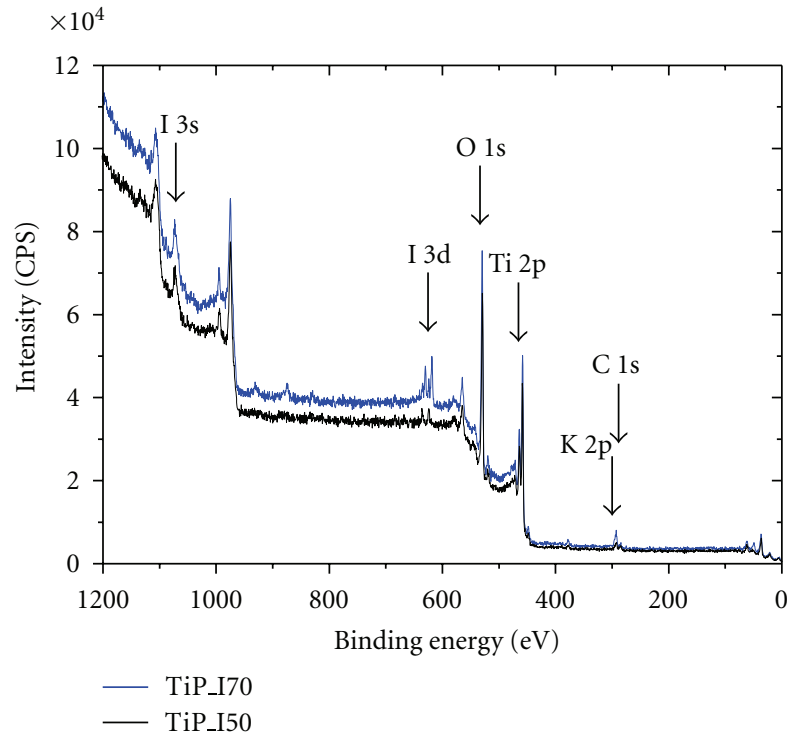

(a)

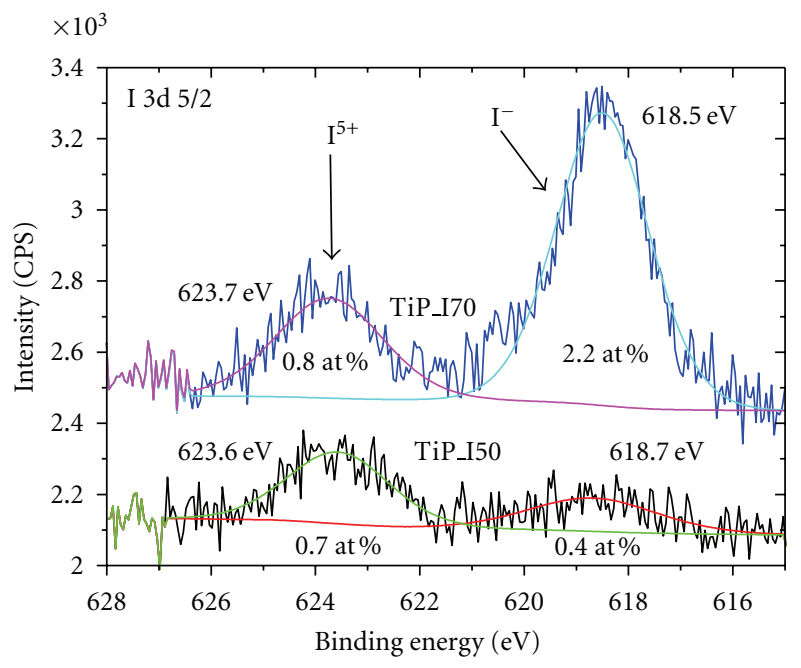

(b)

FIgURE 5: XPS survey spectrum (a) and high-resolution scan over I 3d (b) of samples TiP_I50 and TiP_I70.

and the band at $1625 \mathrm{~cm}^{-1}$ correspond to surface absorbed water and the hydroxyl groups [42]. Both observed peaks are recognized as an important factor affecting photocatalytic activity [43]. The small peak at $\sim 1380 \mathrm{~cm}^{-1}$ can be assigned to surface carbonates formed by adsorption of atmospheric $\mathrm{CO}_{2}$ [44]. Low-frequency bands in the range $<500 \mathrm{~cm}^{-1}$ correspond to the Ti-O-Ti vibration of the network [45]. No other peaks are identified; therefore, the iodine atoms could substitute Ti atoms in all series TiP_I samples.

The XPS spectra (Figure 5(a)) for the sample denoted as TiP_I50 and TiP_I70 show peaks of binding energy for Ti 2p, I 3s, I 3d, O 1s C 1s, and K 2p. To investigate the chemical states of titanium and iodine, we analyzed the highresolution XPS spectra of Ti $2 \mathrm{p} \mathrm{I} 3 \mathrm{~s}$ and I $3 \mathrm{~d}$, and the results are shown in Figure 5(b). There are doublet peaks of I 3d observed at the binding energy around 618.5 and $623.7 \mathrm{eV}$. According to recent published papers, $[15,46]$, the peak of I $3 \mathrm{~d} 5 / 2$ at $623.7 \mathrm{eV}$ can be attributed to $\mathrm{I}^{5+}$ allowing replacing $\mathrm{Ti}^{4+}$ in $\mathrm{TiO}_{2}$ matrix. The other peak detected at $618.5 \mathrm{eV}$ may be originated from $\mathrm{I}^{-}$species, in agreement with the results reported by Su et al. [16]. The occurrence of potassium is caused by input KI, and carbon contamination is from the atmosphere and are very low.

TEM images of iodine-doped titania nanocrystals incorporated into anatase particles are shown in Figure 6. The aspect ratio of anatase particles decreased gradually with the addition of iodine, which changes the morphology of the particles from spindle shaped to rectangular or square shaped particles. The interlayer spacing $\mathrm{d} 101$ of the anatase are extended due to incorporation of iodine atoms. The all interlayer spacing presented in Figure 6 have value about $\sim 0.36 \mathrm{~nm}$ and correspond to crystal faces (101). However, on the basis of the geometries of anatase $\mathrm{TiO}_{2},(101)$ should consist of the end surface of the rods [47] and the lateral surface should be $(010)[48,49]$. On the basis of detail from high-resolution transmission electron microscopy (HRTEM) of nondoped anatase presented in Figure 7(a), they have lattice spacing $\mathrm{d} 101=0.35$ and $\mathrm{d} 002=0.48 \mathrm{~nm}$. The doped anatase nanocrystals show lattice spacings of $\mathrm{d} 101=$ $0.36 \mathrm{~nm}$ for the (101) plane, $\mathrm{d} 100=0.38 \mathrm{~nm}$ for the $(100)$ plane, and $\mathrm{d} 002=0.48 \mathrm{~nm}$ for the (002) plane determined using FFT transformation (see Figure $7(\mathrm{~b})$ ). This result indicates that the basal plane of the spindle-like anatase nanocrystals corresponds to the (010) plane that is vertical to the (010) direction [50]. This result suggested that these anatase nanocrystals have a large aspect ratio of width to thickness and the anatase nanocrystals are extended due to incorporation of iodine atoms, or by formation of lattice vacancies related to iodine incorporation to the structure. With the increasing amount of dopant leads to increase in area (010) surfaces at the expense (101) and (10-1) and thus changes the morphology of the anatase crystal.

The HRTEM images show very clearly the crystalline materials, which contain no amorphous domains. The absence of amorphous domains is an essential prerequisite for good photocatalytic properties. The selected area electron diffraction patterns (SAED), presented in Figure 8, analyzed by the Process Diffraction program confirmed that the structure of all samples is anatase (ICDD PDF 21-1272).

Figure 9 presents UV/vis absorption spectra of the iodine-doped $\mathrm{TiO}_{2}$. Compared with pure titania, the absorption edges of the iodine-doped titania samples are red-shifted; the absorption tail extends to $\sim 600-700 \mathrm{~nm}$, as Figure 9 shows. The red shift of the absorption edge implied a decrease in the band gap energy. It is clear that doping led to a modification of the electronic structure around the conduction band edge of $\mathrm{TiO}_{2}$, resulting in band gap narrowing. With the increasing content of iodine, the prepared samples acquire a yellowish tinge, while the sample marked TiP_70 is pale yellow. 

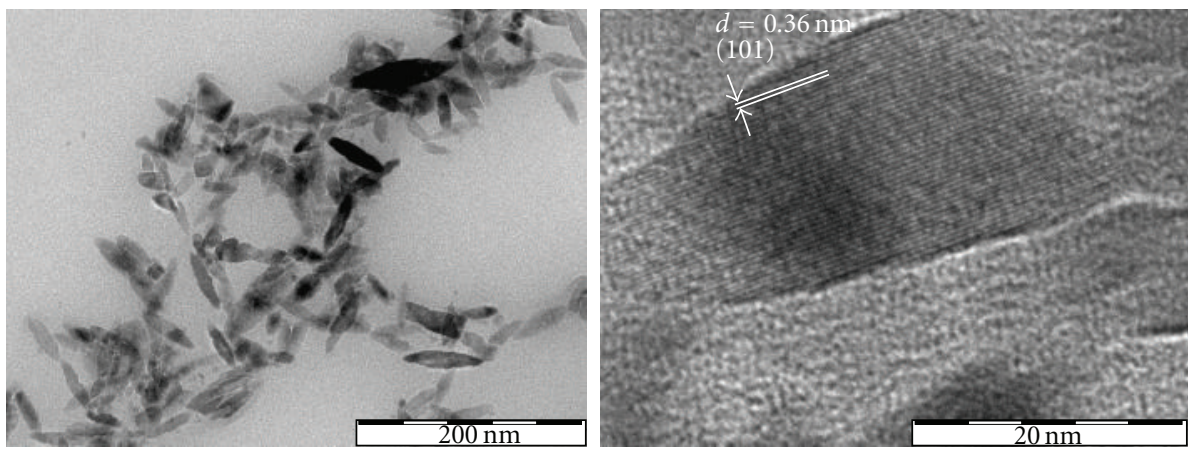

(a)
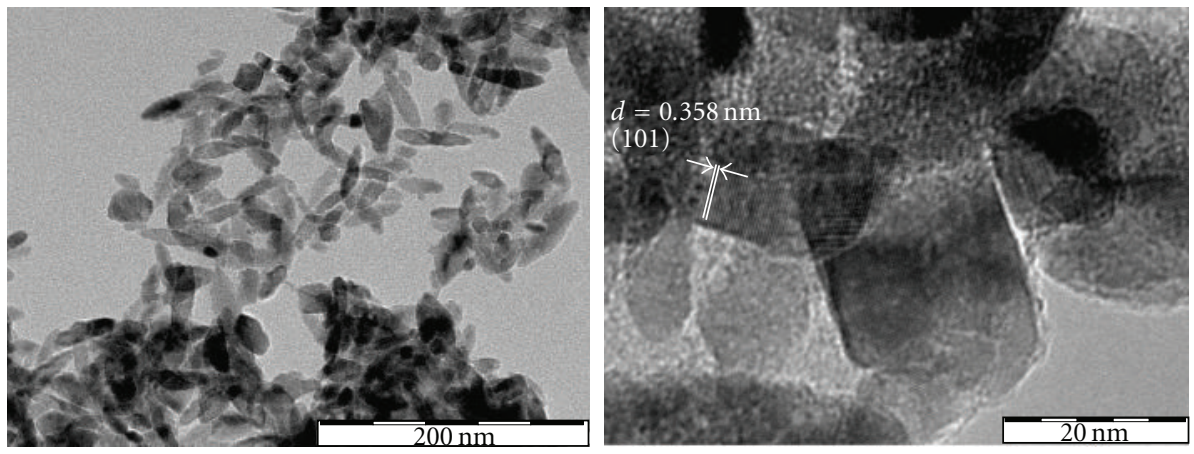

(b)
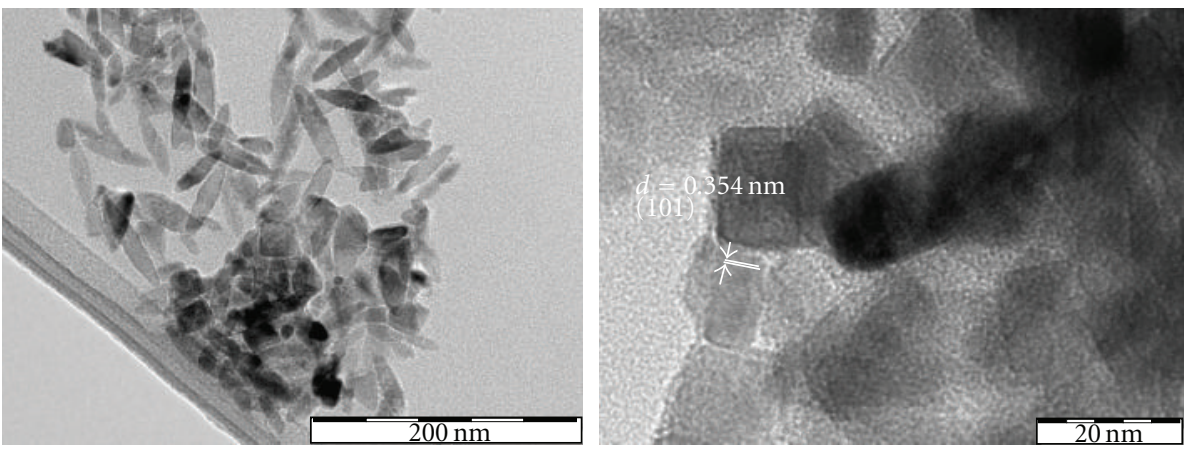

(c)
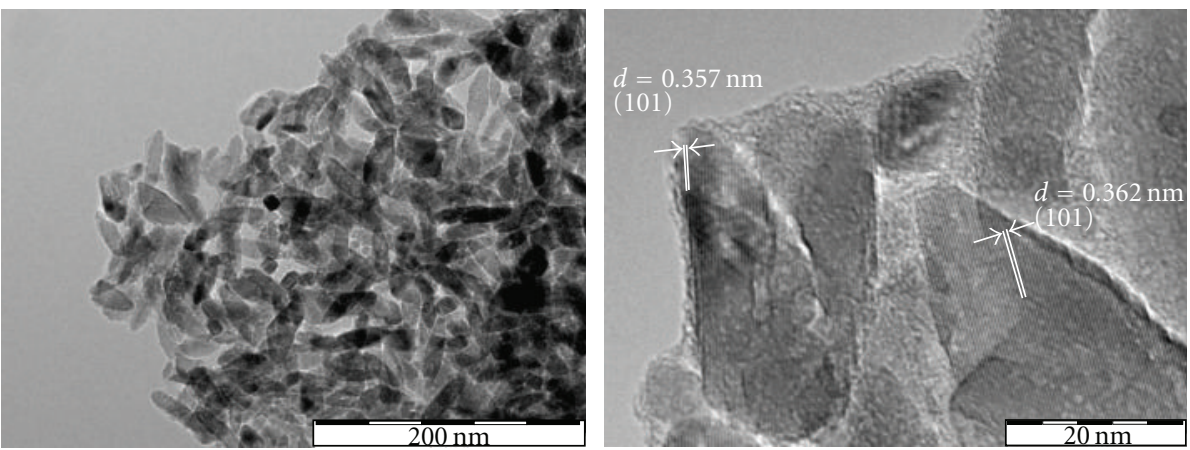

(d)

Figure 6: TEM images of iodine doped $\mathrm{TiO}_{2}$ (a) TiP_I03, (b) TiP_I05, (c) TiP_I10, and (d) TiP_I30. 


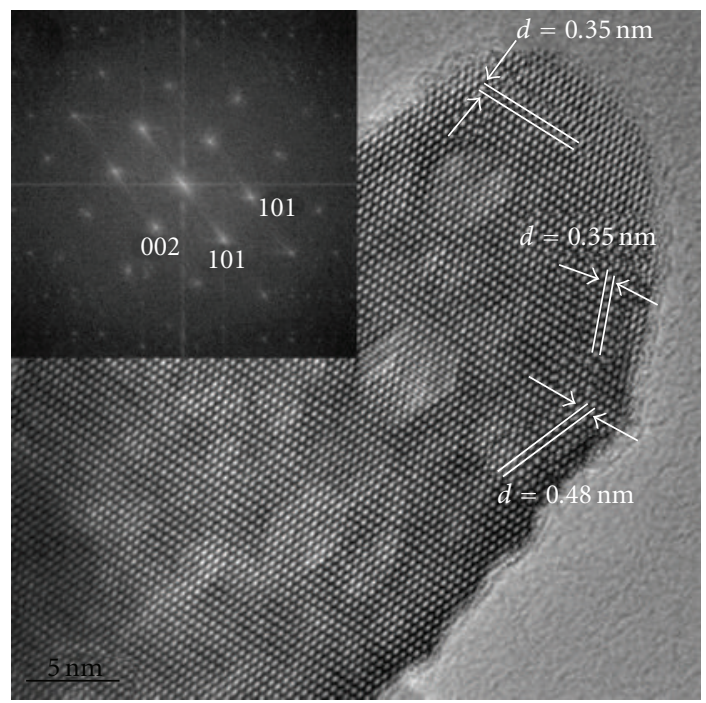

(a)

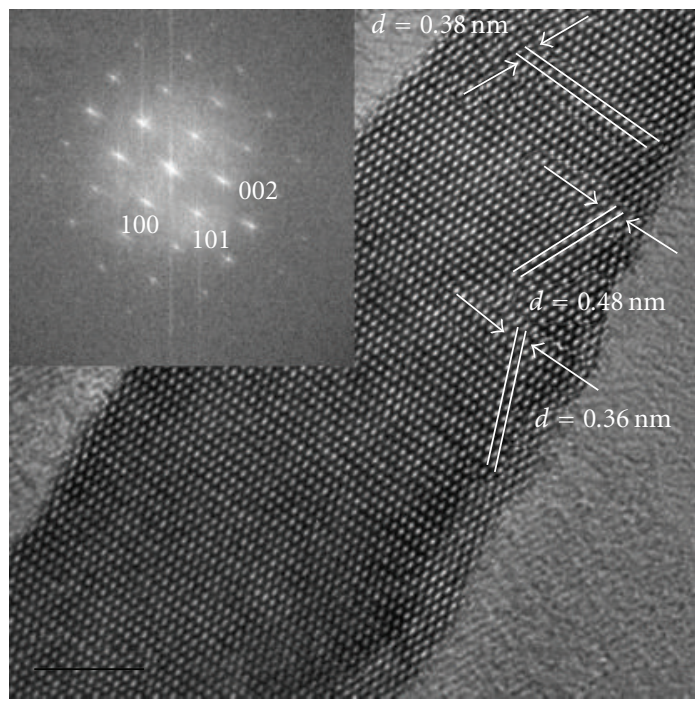

(b)

FIgure 7: HRTEM images of (a) nondoped $\mathrm{TiO}_{2}$ and (b) doped $\mathrm{TiO}_{2}$. Inset FFT.



(a)

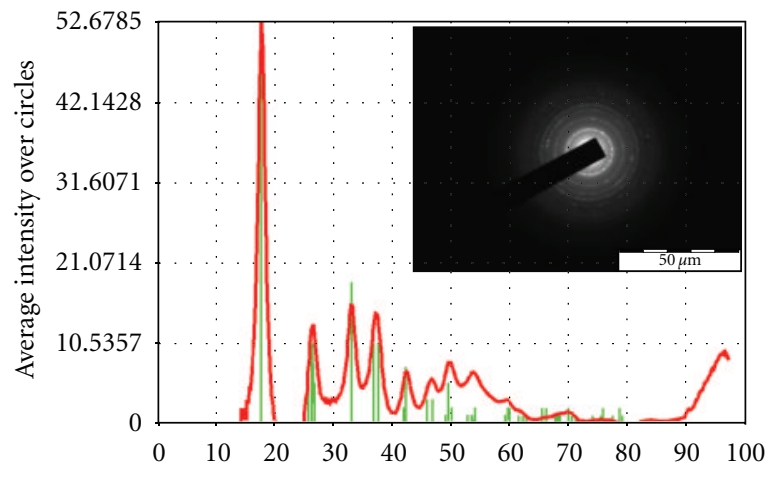

Scattering vector $(=2 \pi / d)(=2 \pi * 2 * \sin \{\theta B\} / \lambda)(1 / \mathrm{nm})$

(c)

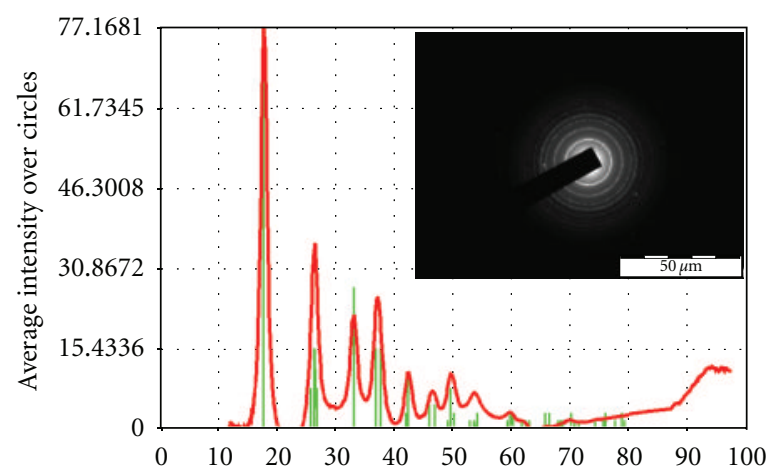

Scattering vector $(=2 \pi / d)(=2 \pi * 2 * \sin \{\theta B\} / \lambda)(1 / \mathrm{nm})$

(b)

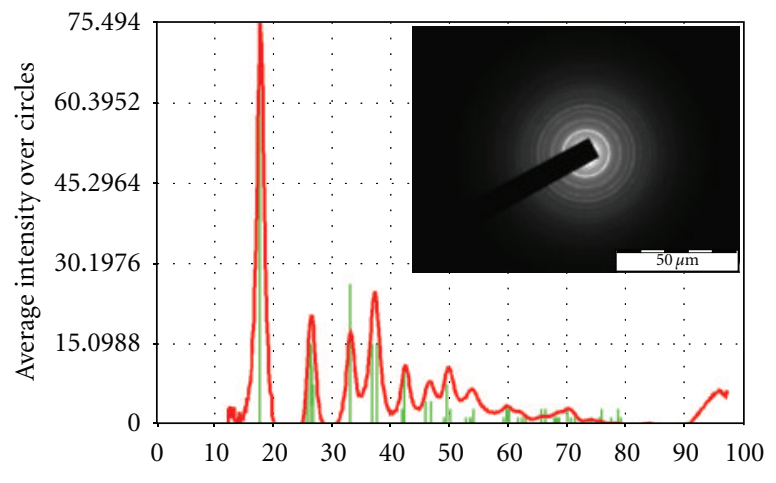

Scattering vector $(=2 \pi / d)(=2 \pi * 2 * \sin \{\theta B\} / \lambda)(1 / \mathrm{nm})$

(d)

Figure 8: SAED images of iodine-doped $\mathrm{TiO}_{2}$ (a) TiP_I03, (b) TiP_I05, (c) TiP_I10, and (d) TiP_I30. 




Figure 9: UV/Vis absorption spectra of the iodine-doped $\mathrm{TiO}_{2}$.

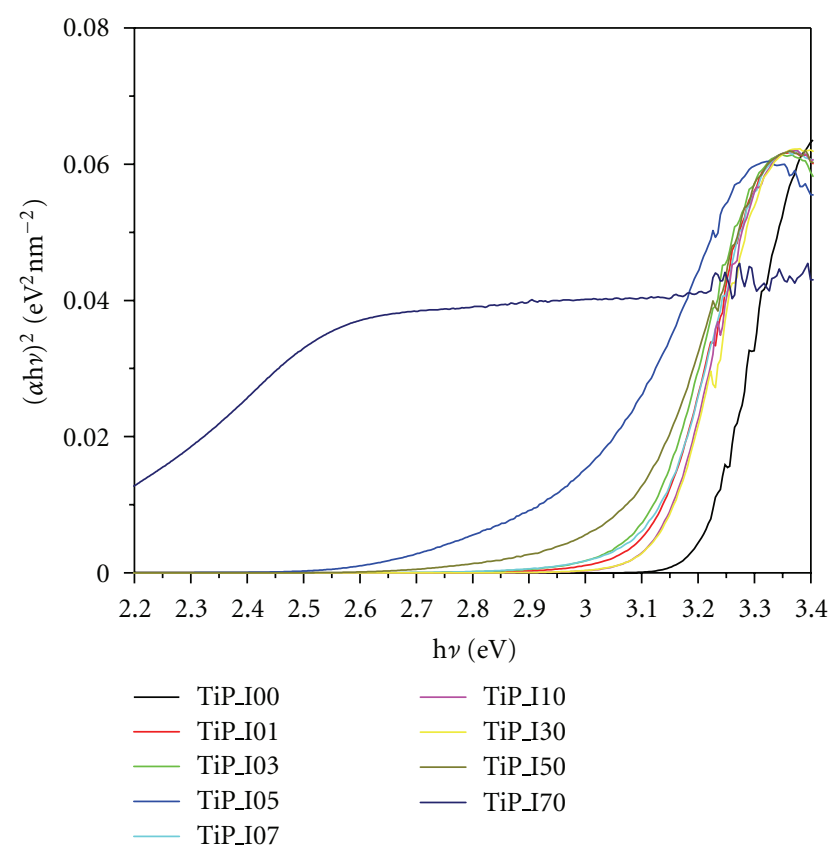

FIgURE 10: Band-gap energy of the iodine-doped $\mathrm{TiO}_{2}$.

The diffuse reflectance spectra were transformed by performing a Kubelka-Munk transformation of the measured reflectance according to

$$
A(R)=\frac{(1-R) 2}{2 R}
$$

where $R$ is the reflectance of the "infinitely thick" layer of the solid [51].
The method of UV/VIS diffuse reflectance spectroscopy was used to estimate band-gap energies of the iodine-doped $\mathrm{TiO}_{2}$ samples. To establish the type of band-to-band transition in these synthesized particles, the absorption data were fitted to equations for direct band-gap transitions. The minimum wavelength required to promote an electron depends upon band-gap energy $\mathrm{E}_{\mathrm{bg}}$ which is commonly estimated from UV-Vis absorption spectra by the linear extrapolation of the absorption coefficient to zero using

$$
\alpha(h v)=A\left(h v-\mathrm{E}_{\mathrm{bg}}\right) n,
$$

where $A$ is the absorption according to (2), B is absorption coefficient, and $h v$ is the photon energy in $\mathrm{eV}$ calculated from the wavelength $\lambda$ in nm $[52,53]$

$$
h v=\frac{1239}{\lambda} .
$$

Should fundamental absorption of the titania crystal possess an indirect transition between bands, then $n=2$ is for the direct transition between bands $n=1 / 2[54,55]$. The energy of the band gap is calculated by extrapolating a straight line to the abscissa axis, when $\alpha$ is zero, then $\mathrm{E}_{\mathrm{bg}}=h v$ [56]. Figure 10 shows $(A h v) 2$ versus photon energy for a direct band-gap transition. The resulting extrapolated values of $\mathrm{E}_{\mathrm{bg}}$ for the indirect transitions are listed in Table 2. The value of $3.20 \mathrm{eV}$ for the iodine-free sample denoted as Ti_I0 is reported in the literature for pure anatase nanoparticles [55, 57]. The value of band-gap energy decreases by increasing the content of iodine dopant.

According to the degradation pathway proposed by [58], the main byproducts formed by the ozonation of azo-dye are organic acids, aldehydes, ketones, and carbon dioxide. Demirev and Nenov, [59] have suggested that the eventual degradation products of azo dye in the ozonation system would be acetic, formic and oxalic acids. The reaction pathway for the visible light-driven photocatalytic degradation of Orange II dye in aqueous $\mathrm{TiO}_{2}$ suspensions is schematically shown in [60].

On the kinetics of heterogeneous photocatalysis for decomposition of model compounds such as dyes Orange II can be used the Langmiur-Hinshelwood equation $[61,62]$ :

$$
r=-d \frac{[\mathrm{OII}]}{d t}=-k_{r} \cdot K \cdot \frac{[\mathrm{OII}]}{1}+K \cdot[\mathrm{OII}],
$$

where $r$ is the degree of dye mineralization, $k_{r}$ the rate constant, $t$ the illumination time, $K$ the adsorption coefficient of the dye, and [OII] the dye concentration. At a very low concentration of the dye, in the validity of Lambert-Beer Law [63]:

$$
A=\varepsilon \cdot c \cdot l,
$$

where $A$ is the absorbance, $c$ the dye concentration, $l$ the length of the absorbent layer and $\varepsilon$ is the molar absorption coefficient, which can simplify (4) to the first-order kinetic equation:

$$
\ln \left(\frac{[\mathrm{OII}]}{[\mathrm{OII}]_{0}}\right)+K\left([\mathrm{OII}]-[\mathrm{OII}]_{0}\right)=-k_{r} \cdot K \cdot t
$$






(a)

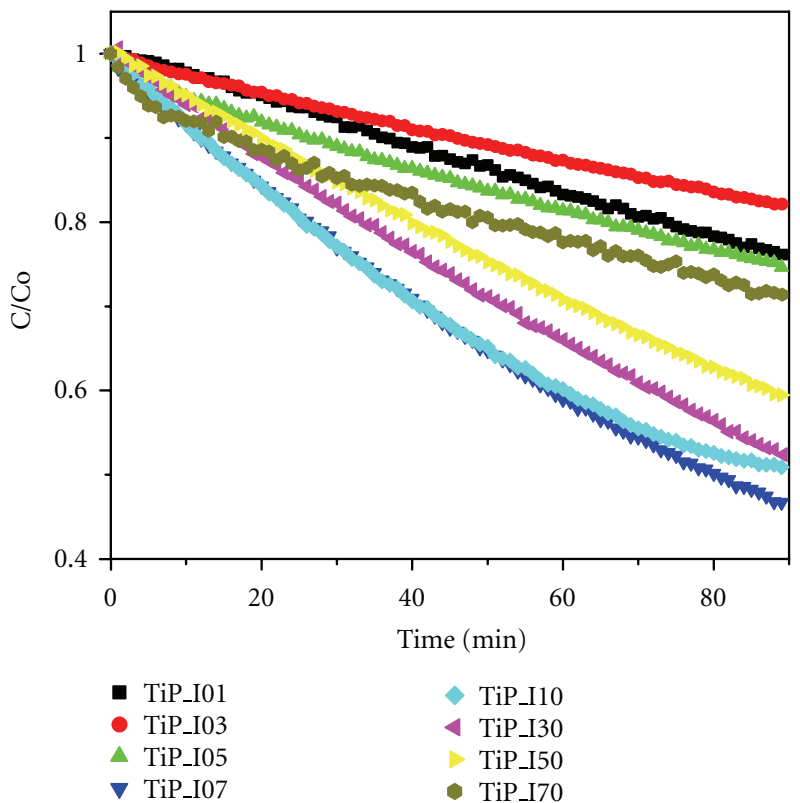

(b)

Figure 11: Photocatalytic degradation of Orange II dye (a) $365 \mathrm{~nm}$, (b) above $400 \mathrm{~nm}$.

and after integration:

$$
[\mathrm{OII}]=[\mathrm{OII}]_{0} \cdot \operatorname{EXP}(-k \cdot t) ; \quad\left(k_{1}=k_{r} \cdot K\right) .
$$

The calculated degradation rate constants $k\left(\mathrm{~min}^{-1}\right)$ are shown in Table 2 and the kinetics of degradation of Orange II dye at $365 \mathrm{~nm}$ (Black light) and $400 \mathrm{~nm}$ (Warm white) on samples TiI_01-TiI_70 are illustrated in Figure 11. Photocatalytic activity in the UV region is dependent on iodine content and increases with its concentration. The sample marked Ti_I30, which contains $\sim 0.2$ wt. $\%$ of iodine shows the highest photocatalytic activity with rate constant $k=0.08513 \mathrm{~min}^{-1}$. The photocatalytic efficiency of iodine doped $\mathrm{TiO}_{2}$ is twice good as Mo- [64] doped titania $\left(k=0.0461 \mathrm{~min}^{-1}\right)$, the same as Ta-doped titania $\left(k=0.0829 \mathrm{~min}^{-1}\right)$ and less then $\mathrm{Nb}$ doped titania $\left(k=0.257 \mathrm{~min}^{-1}\right)[65]$ prepared with the same method. Compared with the P25 $\left(k=0.047 \mathrm{~min}^{-1}\right)[66]$ is Idoped twice higher.

As indicated in Table 2, the nondoped anatase (sample TiP_I00) exhibits very low visible-light photocatalytic activity for the degradation of Orange II dye. The low photocatalytic activity of titania in the visible region is caused by an excessively high band-gap energy of pure anatase $(3.2 \mathrm{eV}$, $\lambda \mathrm{bg}=388 \mathrm{~nm})$. All prepared I-doped samples have higher activity than the nondoped sample (TiP_I00) in irradiation by visible light, which can be actually attributed to the lower band-gap energy (see Table 2). The photocatalytic efficiency in the visible light area is best for the sample denoted TiP_I07 $\left(k=0.00859 \mathrm{~min}^{-1}\right)$ and is comparable with $\mathrm{Mo}-(k=$ $\left.0.0096 \mathrm{~min}^{-1}\right)$ and $\mathrm{Nb}-\left(k=0.0090 \mathrm{~min}^{-1}\right)$ or the Ta- $(k=$ $0.0070 \mathrm{~min}^{-1}$ ) doped titania.

Nonmetal cationic doping is a feasible strategy for developing highly efficient UV and visible-light responsive photocatalysts. Doping of halogen atoms was found to be
TABLE 2: Band-gap energy and rate constant k1 of I-doped titania.

\begin{tabular}{cccc}
\hline Sample & $\mathrm{E}_{\mathrm{bg}}[\mathrm{eV}]$ & $\mathrm{k}$ OII $365 \mathrm{~nm}\left[\mathrm{~min}^{-1}\right]$ & $\mathrm{k}$ OII $400 \mathrm{~nm}\left[\mathrm{~min}^{-1}\right]$ \\
\hline TiP_I01 & 3.20 & 0.03363 & 0.00315 \\
TiP_I03 & 3.10 & 0.01297 & 0.00219 \\
TiP_I05 & 3.10 & 0.01905 & 0.00311 \\
TiP_I07 & 3.10 & 0.04244 & $\mathbf{0 . 0 0 8 5 9}$ \\
TiP_I10 & 3.05 & 0.05286 & 0.00757 \\
TiP_I30 & 3.00 & $\mathbf{0 . 0 8 5 1 3}$ & 0.00731 \\
TiP_I50 & 2.90 & 0.05604 & 0.00591 \\
TiP_I70 & 1.90 & 0.03746 & 0.00335 \\
\hline
\end{tabular}

effective, because the impurity states of halogen ions are near the valence band edge, but they do not act as charge carriers, and their role as recombination centers might be minimized compared to metal cation doping [67].

Figure 12(a) depicts the dependence of the rate constant of dye degradation on the molar amount of iodine obtained from the EDX analysis. The highest rate constant at UV light $(365 \mathrm{~nm})$ is observed in sample TiP_I30 with $0.20 \mathrm{wt} . \%$ of iodine, which correspond to significant change of cell parameters (Figure 12(b)) - the increase of cell parameter a and parallel decrease of cell parameter c. The sample TiP_I07 with 0.32 wt. $\%$ of iodine exhibit the highest rate constant at a light wavelength above $400 \mathrm{~nm}$. This increase of rate constant is accompanied with a change of cell parameters in the opposite way (i.e., lowering of cell parameter a, increasing of cell parameter, b) to the sample TiP_I30 with highest rate constant in UV light. At this point, increased absorbance of visible light (see Figure 12(c)) also corresponds to the higher photocatalytic activity by visible light illumination. During the final stage, where the amount of iodine gets 


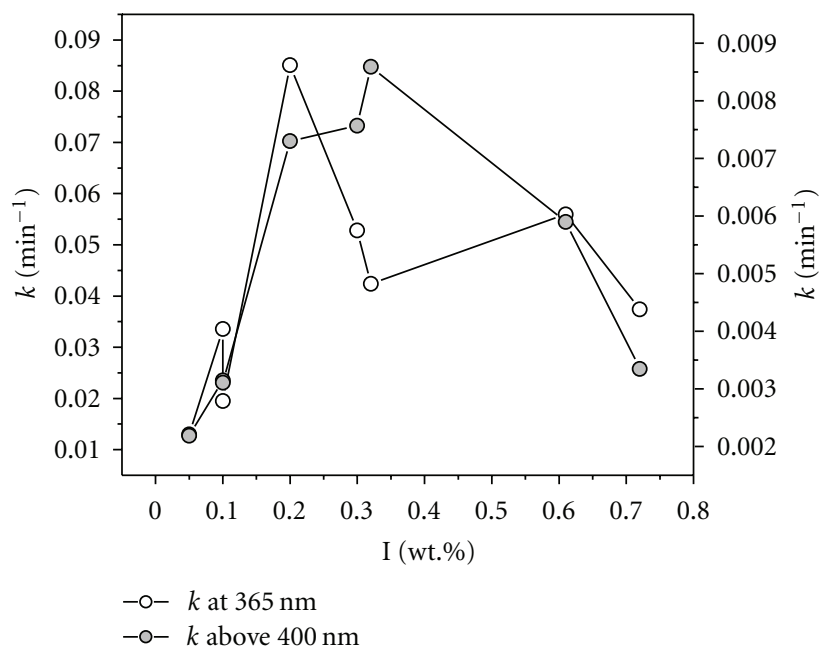

(a)

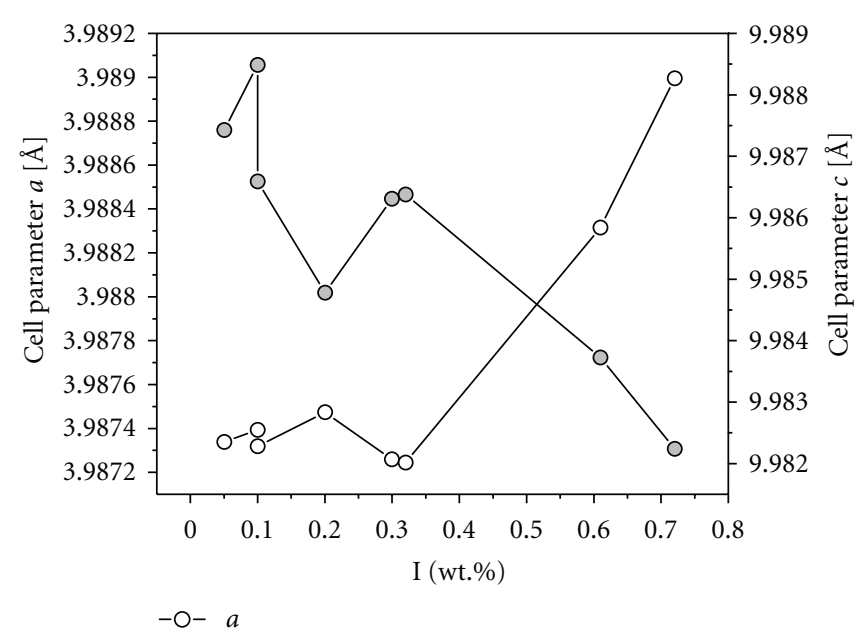

(b)

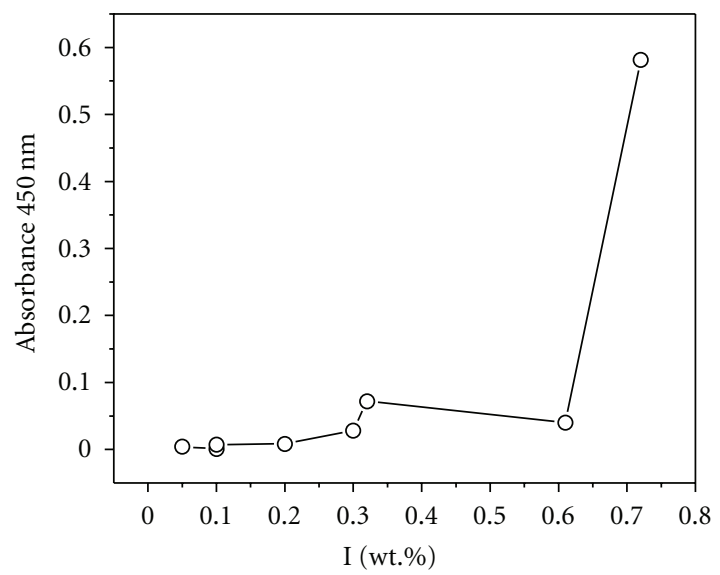

(c)

Figure 12: Dependence of the content of I dopant [wt \%] of (a) rate constant $k$, (b) cell parameters $a$ and $c$, and (c) absorbance at $450 \mathrm{~nm}$.

higher rapid changes of cell parameters and growth of visible light absorbance connected with decrease of photoactivity in both, UV and visible light regions are seen.

\section{Conclusion}

The doped titania samples were prepared from aqueous solutions by thermal hydrolysis of KI and Ti peroxo-complexes. The thermal hydrolysis of a peroxo-complex has one great advantage over other reaction processes, namely, that the reaction takes place in a one-step process and the byproduct is pure water. Another great advantage of this procedure could be its easy transfer to low-cost manufacture of a photocatalytic pigment. The prepared monodispersed particles have a mesoporous character with a pore size distribution of 10-20 nm. Incorporation of iodine ions into the crystal lattice of anatase $\mathrm{TiO}_{2}$ changes the morphology of particles from spindle shaped to rectangular or those square. Structural investigation on the basis of X-ray diffraction as well as SAED in high-resolution transmission electron microscopy confirms a well-developed crystal structure with an interlayer distance $\mathrm{d} 101=0.354-0.360 \mathrm{~nm}$, which indicates crystal lattice expansion due to the incorporation of iodine dopants. The iodine addition increases the photocatalytic activity of titania in the visible light region.

\section{Acknowledgments}

This work was supported by the Academy of Sciences of the Czech Republic (Project no. AV OZ 40320502) and Czech Science Foundation (Project no. 203/08/0334). The authors wish to thank K. Šafářvá of the Regional Centre of Advanced Technologies and Materials, Faculty of Science, Palacký University in Olomouc, for providing HRTEM measurements, M. Kormunda of the Department of Physics, Faculty of Science, J. E. Purkinje University, for XPS measurement, and P. Bezdička of the Institute of Inorganic Chemistry AS CR v.v.i., Husinec-Řež, for doing XRD measurements.

\section{References}

[1] J. A. Zheng, Z. Q. Liu, X. Liu, X. Yan, D. D. Li, and W. Chu, "Facile hydrothermal synthesis and characteristics of B-doped 
$\mathrm{TiO}_{2}$ hybrid hollow microspheres with higher photo-catalytic activity," Journal of Alloys and Compounds, vol. 509, no. 9, pp. 3771-3776, 2011.

[2] Y. Park, W. Kim, H. Park, T. Tachikawa, T. Majima, and W. Choi, "Carbon-doped $\mathrm{TiO}_{2}$ photocatalyst synthesized without using an external carbon precursor and the visible light activity," Applied Catalysis B, vol. 91, no. 1-2, pp. 355-361, 2009.

[3] J. B. Varley, A. Janotti, and C. G. Van de Walle, "Mechanism of visible-light photocatalysis in nitrogen-doped $\mathrm{TiO}_{2}$, " Advanced Materials, vol. 23, no. 20, pp. 2343-2347, 2011.

[4] H. Tian, J. Ma, K. Li, and J. J. Li, "Hydrothermal synthesis of Sdoped $\mathrm{TiO}_{2}$ nanoparticles and their photocatalytic ability for degradation of methyl orange," Ceramics International, vol. 35, no. 3, pp. 1289-1292, 2009.

[5] C. Yu, D. Cai, K. Yang, J. C. Yu, Y. Zhou, and C. Fan, "Solgel derived S,I-codoped mesoporous $\mathrm{TiO}_{2}$ photocatalyst with high visible-light photocatalytic activity," Journal of Physics and Chemistry of Solids, vol. 71, no. 9, pp. 1337-1343, 2010.

[6] E. M. Rockafellow, J. M. Haywood, T. Witte, R. S. Houk, and W. S. Jenks, "Selenium-modified $\mathrm{TiO}_{2}$ and its impact on photocatalysis," Langmuir, vol. 26, no. 24, pp. 19052-19059, 2010.

[7] J. W. Zheng, A. Bhattcahrayya, P. Wu et al., "The origin of visible light absorption in chalcogen element (S, Se, and Te)-doped anatase $\mathrm{TiO}_{2}$ photoatalysts," Journal of Physical Chemistry C, vol. 114, no. 15, pp. 7063-7069, 2010.

[8] G. J. Ren, Y. A. Gao, X. Liu, A. Xing, H. T. Liu, and J. G. Yin, "Synthesis of high-activity F-doped $\mathrm{TiO}_{2}$ photocatalyst via a simple one-step hydrothermal process," Reaction Kinetics, Mechanisms and Catalysis, vol. 100, no. 2, pp. 487-497, 2010.

[9] M. L. Guo, X. D. Zhang, C. T. Liang, and G. Z. Jia, "Mechanism of visible photoactivity of F-doped $\mathrm{TiO}_{2}$," Chinese Physics Letters, vol. 27, no. 5, Article ID 057103, 2010.

[10] M. Long, W. Cai, H. Chen, and J. Xu, "Preparation, characterization and photocatalytic activity of visible light driven chlorine-doped $\mathrm{TiO}_{2}$," Frontiers of Chemistry in China, vol. 2, no. 3, pp. 278-282, 2007.

[11] H. Xu, Z. Zheng, L. Zhang, H. Zhang, and F. Deng, "Hierarchical chlorine-doped rutile $\mathrm{TiO}_{2}$ spherical clusters of nanorods: large-scale synthesis and high photocatalytic activity," Journal of Solid State Chemistry, vol. 181, no. 9, pp. 2516-2522, 2008.

[12] H. Luo, T. Takata, Y. Lee, J. Zhao, K. Domen, and Y. Yan, "Photocatalytic activity enhancing for titanium dioxide by codoping with bromine and chlorine," Chemistry of Materials, vol. 16, no. 5, pp. 846-849, 2004.

[13] H. Sun, S. Wang, H. M. Ang, M. O. Tadé, and Q. Li, "Halogen element modified titanium dioxide for visible light photocatalysis," Chemical Engineering Journal, vol. 162, no. 2, pp. 437-447, 2010.

[14] S. Tojo, T. Tachikawa, M. Fujitsuka, and T. Majima, "Iodinedoped $\mathrm{TiO}_{2}$ photocatalysts: correlation between band structure and mechanism," Journal of Physical Chemistry C, vol. 112, no. 38, pp. 14948-14954, 2008.

[15] X. Hong, Z. Wang, W. Cai et al., "Visible-light-activated nanoparticle photocatalyst of iodine-doped titanium dioxide," Chemistry of Materials, vol. 17, no. 6, pp. 1548-1552, 2005.

[16] W. Y. Su, Y. F. Zhang, Z. H. Li et al., "Multivalency iodine doped $\mathrm{TiO}_{2}$ : preparation, characterization, theoretical studies, and visible-light photocatalysis," Langmuir, vol. 24, no. 7, pp. 3422-3428, 2008.

[17] Q. Zhang, Y. Li, E. A. Ackerman, M. Gajdardziska-Josifovska, and $\mathrm{H}$. Li, "Visible light responsive iodine-doped $\mathrm{TiO}_{2}$ for photocatalytic reduction of $\mathrm{CO}_{2}$ to fuels," Applied Catalysis A, vol. 400, no. 1-2, pp. 195-202, 2011.
[18] G. Liu, C. Sun, X. Yan et al., "Iodine doped anatase $\mathrm{TiO}_{2}$ photocatalyst with ultra-long visible light response: correlation between geometric/electronic structures and mechanisms," Journal of Materials Chemistry, vol. 19, no. 18, pp. 2822-2829, 2009.

[19] G. Liu, Z. Chen, C. Dong et al., "Visible light photocatalyst: iodine-doped mesoporous titania with a bicrystalline framework," Journal of Physical Chemistry B, vol. 110, no. 42, pp. 20823-20828, 2006.

[20] Y. Ma, J. W. Fu, X. Tao, X. Li, and J. F. Chen, "Low temperature synthesis of iodine-doped $\mathrm{TiO}_{2}$ nanocrystallites with enhanced visible-induced photocatalytic activity," Applied Surface Science, vol. 257, no. 11, pp. 5046-5051, 2011.

[21] C. Wen, Y. J. Zhu, T. Kanbara, H. Z. Zhu, and C. F. Xiao, "Effects of I and $\mathrm{F}$ codoped $\mathrm{TiO}_{2}$ on the photocatalytic degradation of methylene blue," Desalination, vol. 249, no. 2, pp. 621-625, 2009.

[22] S. Song, J. Tu, L. Xu et al., "Preparation of a titanium dioxide photocatalyst codoped with cerium and iodine and its performance in the degradation of oxalic acid," Chemosphere, vol. 73, no. 9, pp. 1401-1406, 2008.

[23] S. Song, C. Wang, F. Y. Hong, Z. Q. He, Q. L. Cai, and J. M. Chen, "Gallium- and iodine-co-doped titanium dioxide for photocatalytic degradation of 2-chlorophenol in aqueous solution: role of gallium," Applied Surface Science, vol. 257, no. 8, pp. 3427-3432, 2011.

[24] X. Jiang, L. Yang, P. Liu, X. Li, and J. Shen, "The photocatalytic and antibacterial activities of neodymium and iodine doped $\mathrm{TiO}_{2}$ nanoparticles," Colloids and Surfaces B, vol. 79, no. 1, pp. 69-74, 2010.

[25] S. Anandan, K. Kathiravan, V. Murugesan, and Y. Ikuma, "Anionic (IO3-) non-metal doped $\mathrm{TiO}_{2}$ nanoparticles for the photocatalytic degradation of hazardous pollutant in water," Catalysis Communications, vol. 10, no. 6, pp. 1014-1019, 2009.

[26] J. Pan, G. Liu, G. Q. Lu, and H.-M. Cheng, "On the true photoreactivity order of 001, 010, and 101 facets of anatase $\mathrm{TiO}_{2}$ crystals," Angewandte Chemie-International Edition, vol. 50, no. 9, pp. 2133-2137, 2011.

[27] JCPDS, PDF 2 Database, Release 50, International Centre for Diffraction Data, Newtown Square, 2000.

[28] ICSD, ICSD Database FIZ Karlsruhe, Germany, 2008.

[29] S. Brunauer, P. H. Emmett, and E. Teller, "Adsorption of gases in multimolecular layers," Journal of the American Chemical Society, vol. 60, no. 2, pp. 309-319, 1938.

[30] E. P. Barrett, L. G. Joyner, and P. P. Halenda, "The determination of pore volume and area distributions in porous substances: I. Computations from nitrogen isotherms," Journal of the American Chemical Society, vol. 73, no. 1, pp. 373-380, 1951.

[31] Z. C. Orel, M. K. Gunde, and B. Orel, "Application of the Kubelka-Munk theory for the determination of the optical properties of solar absorbing paints," Progress in Organic Coatings, vol. 30, no. 1-2, pp. 59-66, 1997.

[32] H. Lachheb, E. Puzenat, A. Houas et al., "Photocatalytic degradation of various types of dyes (Alizarin S, Crocein Orange G, Methyl Red, Congo Red, Methylene Blue) in water by UVirradiated titania," Applied Catalysis B, vol. 39, no. 1, pp. 7590, 2002.

[33] J. M. Monteagudo and A. Durán, "Fresnel lens to concentrate solar energy for the photocatalytic decoloration and mineralization of orange II in aqueous solution," Chemosphere, vol. 65, no. 7, pp. 1242-1248, 2006. 
[34] V. Štengl, V. Houšková, S. Bakardjieva, N. Murafa, and V. Havlín, "Optically transparent titanium dioxide particles incorporated in poly(hydroxyethyl methacrylate) thin layers," Journal of Physical Chemistry C, vol. 112, no. 50, pp. 1997919985, 2008.

[35] Y. L. Su, Y. T. Xiao, Y. X. Du, and S. A. Fu, "I-doping of anodized $\mathrm{TiO}_{2}$ nanotubes using an electrochemical method," Chinese Science Bulletin, vol. 55, no. 20, pp. 2136-2141, 2010.

[36] R. C. Pullar, S. J. Penn, X. Wang, I. M. Reaney, and N. M. Alford, "Dielectric loss caused by oxygen vacancies in titania ceramics," Journal of the European Ceramic Society, vol. 29, no. 3, pp. 419-424, 2009.

[37] S. Lowell and J. E. Shields, Powder Surface Area and Porosity, London, UK, 1998.

[38] D. H. Everett and F. S. Stone, Eds., Structure \& Properties of Porous Materials, Butterworths, London, UK, 1958.

[39] K.-R. Zhu, M.-S. Zhang, Q. Chen, and Z. Yin, "Size and phonon-confinement effects on low-frequency Raman mode of anatase $\mathrm{TiO}_{2}$ nanocrystal," Physics Letters A, vol. 340, no. 1-4, pp. 220-227, 2005.

[40] S. W. Lu, C. Harris, S. Walck, and M. Arbab, "Phase sensitivity of Raman spectroscopy analysis of CVD titania thin films," Journal of Materials Science, vol. 44, no. 2, pp. 541-544, 2009.

[41] V. Štengl, S. Bakardjieva, N. Murafa, E. Večerníková, J. Šubrt, and V. Balek, "Preparation and characterization of titania based nanowires," Journal of Nanoparticle Research, vol. 9, no. 3, pp. 455-470, 2007.

[42] G. S. Shao, X. J. Zhang, and Z. Y. Yuan, "Preparation and photocatalytic activity of hierarchically mesoporous-macroporous $\mathrm{TiO}_{2}-\mathrm{xNx}$," Applied Catalysis B, vol. 82, no. 3-4, pp. 208-218, 2008.

[43] Z. Ding, G. Q. Lu, and P. F. Greenfield, "Role of the crystallite phase of $\mathrm{TiO}_{2}$ in heterogeneous photocatalysis for phenol oxidation in water," Journal of Physical Chemistry B, vol. 104, no. 19, pp. 4815-4820, 2000.

[44] P. A. Connor, K. D. Dobson, and A. J. McQuillan, "Infrared spectroscopy of the $\mathrm{TiO}_{2}$ /aqueous solution interface," Langmuir, vol. 15, no. 7, pp. 2402-2408, 1999.

[45] G. Soler-Illia, A. Louis, and C. Sanchez, "Synthesis and characterization of mesostructured titania-based materials through evaporation-induced self-assembly," Chemistry of Materials, vol. 14, no. 2, pp. 750-759, 2002.

[46] S. Song, J. J Tu, Z. Q. He, F. Y. Hong, W. P. Liu, and J. M. Chen, "Visible light-driven iodine-doped titanium dioxide nanotubes prepared by hydrothermal process and post-calcination," Applied Catalysis A, vol. 378, no. 2, pp. 169-174, 2010.

[47] G. Liu, J. C. Yu, G. Q. Lu, and H.-M. Cheng, "Crystal facet engineering of semiconductor photocatalysts: motivations, advances and unique properties," Chemical Communications, vol. 47, no. 24, pp. 6763-6783, 2011.

[48] H. B. Jiang, Q. Cuan, C. Z. Wen et al., "Anatase $\mathrm{TiO}_{2}$ crystals with exposed high-index facets," Angewandte ChemieInternational Edition, vol. 50, no. 16, pp. 3764-3768, 2011.

[49] J. Pan, X. Wu, L. Wang, G. Liu, G. Q. Lu, and H. M. Cheng, "Synthesis of anatase $\mathrm{TiO}_{2}$ rods with dominant reactive 010 facets for the photoreduction of $\mathrm{CO}_{2}$ to $\mathrm{CH}_{4}$ and use in dyesensitized solar cells," Chemical Communications, vol. 47, no. 29, pp. 8361-8363, 2011.

[50] P. Wen, H. Itoh, W. Tang, and Q. Feng, "Single nanocrystals of anatase-type $\mathrm{TiO}_{2}$ prepared from layered titanate nanosheets: formation mechanism and characterization of surface properties," Langmuir, vol. 23, no. 23, pp. 11782-11790, 2007.
[51] A. A. Christy, O. M. Kvalheim, and R. A. Velapoldi, "Quantitative analysis in diffuse reflectance spectrometry: a modified Kubelka-Munk equation," Vibrational Spectroscopy, vol. 9, no. 1, pp. 19-27, 1995.

[52] K. M. Reddy, S. V. Manorama, and A. R. Reddy, "Bandgap studies on anatase titanium dioxide nanoparticles," Materials Chemistry and Physics, vol. 78, no. 1, pp. 239-245, 2003.

[53] J. Tauc, R. Grigorov, and A. Vancu, "Optical properties and electronic structure of amorphous germanium," Physica Status Solidi, vol. 15, no. 2, pp. 627-637, 1966.

[54] D. Reyes-Coronado, G. Rodríguez-Gattorno, M. E. EspinosaPesqueira, C. Cab, R. de Coss, and G. Oskam, "Phase-pure $\mathrm{TiO}_{2}$ nanoparticles: anatase, brookite and rutile," Nanotechnology, vol. 19, no. 14, 2008.

[55] N. Serpone, D. Lawless, and R. Khairutdinov, "Size effects on the photophysical properties of colloidal anatase $\mathrm{TiO}_{2}$ particles: size quantization or direct transitions in this indirect semiconductor?" Journal of Physical Chemistry, vol. 99, no. 45, pp. 16646-16654, 1995.

[56] E. Sanchez and T. Lopez, "Effect of the preparation method on the band gap of titania and platinum-titania sol-gel materials," Materials Letters, vol. 25, no. 5-6, pp. 271-275, 1995.

[57] D. S. Bhatkhande, V. G. Pangarkar, and A. Beenackers, "Photocatalytic degradation for environmental applications-a review," Journal of Chemical Technology and Biotechnology, vol. 77, no. 1, pp. 102-116, 2002.

[58] W. R. Zhao, H. X. Shi, and D. H. Wang, "Ozonation of cationic red X-GRL in aqueous solution: degradation and mechanism," Chemosphere, vol. 57, no. 9, pp. 1189-1199, 2004.

[59] A. Demirev and V. Nenov, "Ozonation of two acidic azo dyes with different substituents," Ozone: Science and Engineering, vol. 27, no. 6, pp. 475-485, 2005.

[60] M. Stylidi, D. I. Kondarides, and X. E. Verykios, "Visible light-induced photocatalytic degradation of acid orange 7 in aqueous $\mathrm{TiO}_{2}$ suspensions," Applied Catalysis B, vol. 47, no. 3 , pp. 189-201, 2004.

[61] Y. Mu, H. Q. Yu, J. C. Zheng, and S. J. Zhang, “ $\mathrm{TiO}_{2}$-mediated photocatalytic degradation of Orange II with the presence of $\mathrm{Mn}^{2+}$ in solution," Journal of Photochemistry and Photobiology A, vol. 163, no. 3, pp. 311-316, 2004.

[62] I. K. Konstantinou and T. A. Albanis, " $\mathrm{TiO}_{2}$-assisted photocatalytic degradation of azo dyes in aqueous solution: kinetic and mechanistic investigations: a review," Applied Catalysis B, vol. 49, no. 1, pp. 1-14, 2004.

[63] Q. L. Yu, M. M. Ballari, and H. J. H. Brouwers, "Indoor air purification using heterogeneous photocatalytic oxidation, part II: kinetic study," Applied Catalysis B, vol. 99, no. 1-2, pp. 58-65, 2010.

[64] V. Štengl and S. Bakardjieva, "Molybdenum-doped anatase and its extraordinary photocatalytic activity in the degradation of orange II in the UV and vis regions," Journal of Physical Chemistry C, vol. 114, no. 45, pp. 19308-19317, 2010.

[65] V. Štengl, V. Houškovǎ, S. Bakardjieva, N. Murafa, and P. Bezdička, "Niobium and tantalum doped titania particles," Journal of Materials Research, vol. 25, no. 10, pp. 2015-2024, 2010.

[66] V. Štengl, S. Bakardjieva, N. Murafa, V. Houšková, and K. Lang, "Visible-light photocatalytic activity of $\mathrm{TiO}_{2} / \mathrm{ZnS}$ nanocomposites prepared by homogeneous hydrolysis," Microporous and Mesoporous Materials, vol. 110, no. 2-3, pp. 370-378, 2008.

[67] H. Wang and J. P. Lewis, "Second-generation photocatalytic materials: anion-doped $\mathrm{TiO}_{2}$," Journal of Physics Condensed Matter, vol. 18, no. 2, pp. 421-434, 2006. 


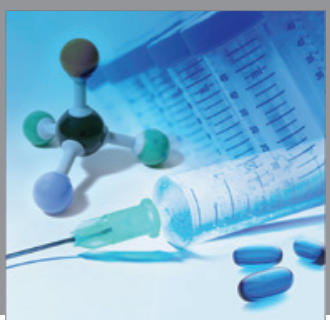

International Journal of

Medicinal Chemistry

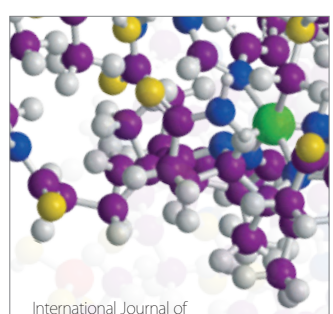

Carbohydrate Chemistry



The Scientific World Journal

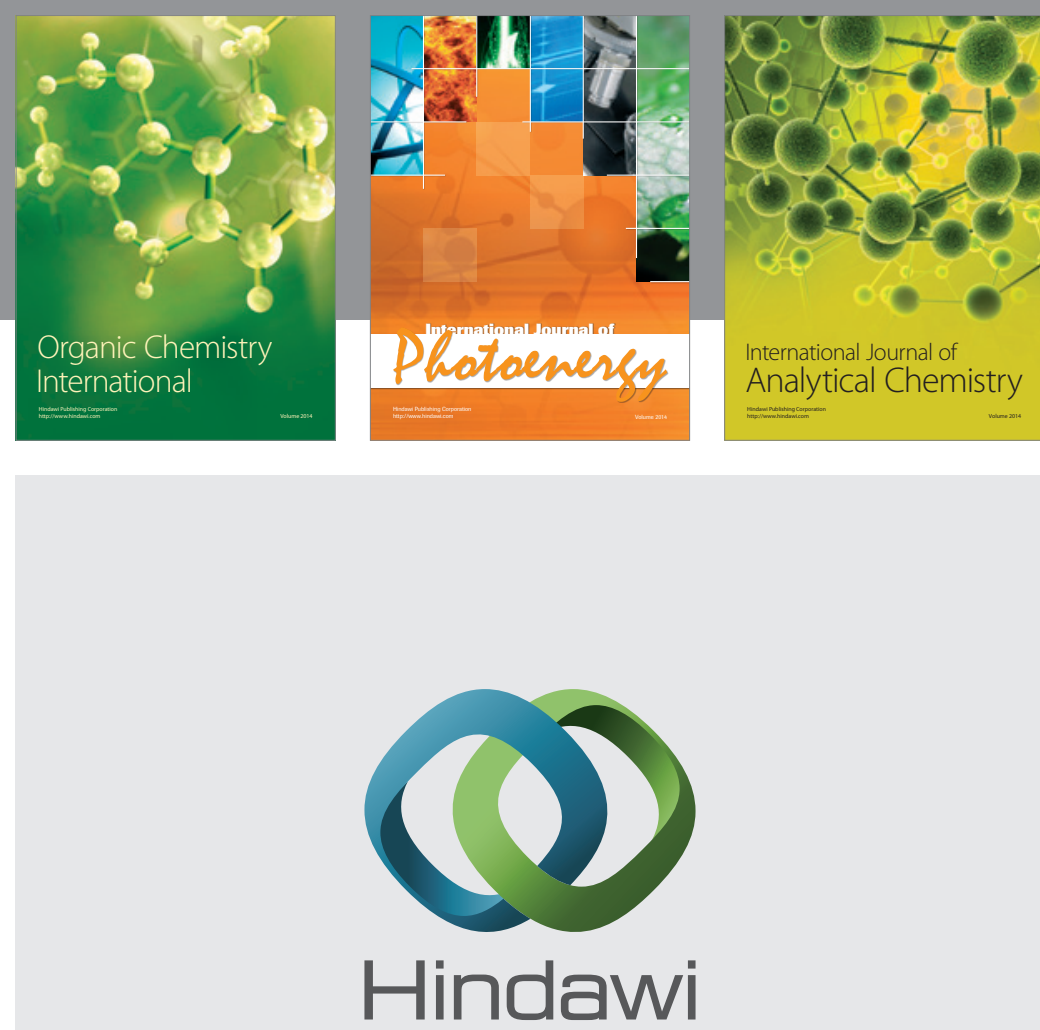

Submit your manuscripts at

http://www.hindawi.com
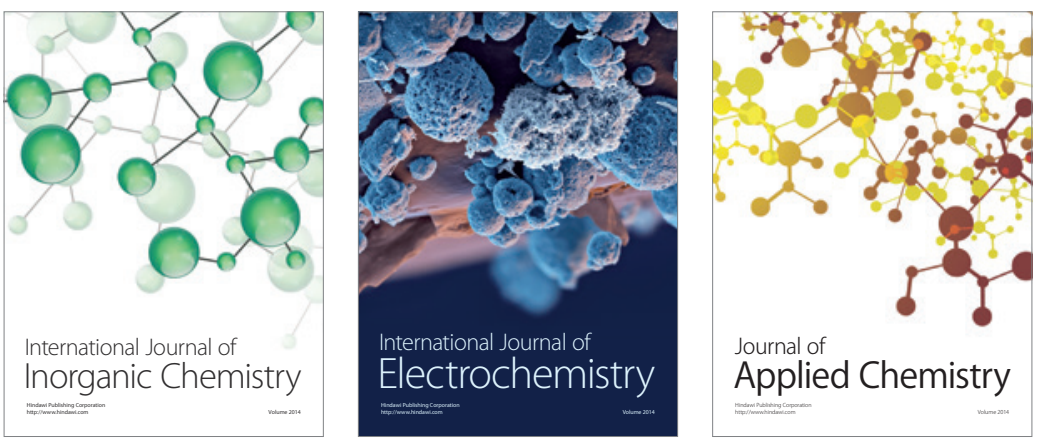

Journal of

Applied Chemistry

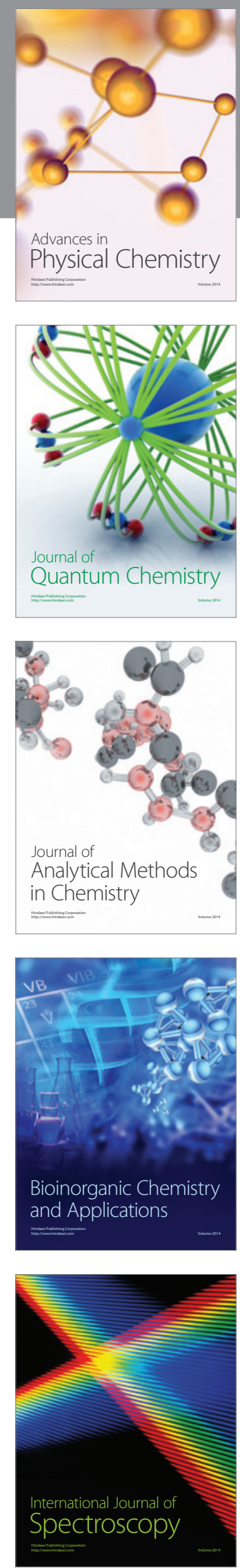